Jurnal Ilmu-Ilmu Peternakan 26 (1): 37 - 42

ISSN : 0852-3681

E-ISSN : 2443-0765

CFakultas Peternakan UB, http://jiip.ub.ac.id/

\title{
Hubungan antara lingkar dada, panjang dan tinggi badan dengan bobot badan kambing Senduro jantan di Kecamatan Senduro, Kabupaten Lumajang
}

\author{
Wahyu Adhi Tama, Moch. Nasich dan Sri Wahyuningsih \\ Fakultas Peternakan, Universitas Brawijaya, Malang \\ Jl. Veteran Malang 65145 Jawa Timur \\ wahyuat.12@gmail.com
}

\begin{abstract}
This research was conducted in Senduro Sub-District, Lumajang from January $24^{\text {th }}$ to February $24^{\text {th }} 2016$. The objective of the study was to determine the relationship between linear body measurement (chest girth (CG), body length (BL) and body height $(\mathrm{BH})$ ) and body weight of Senduro goats. The study used 104 Senduro goats that were categorized as PI0 to PI8. The correlation values between body weight and body measurements ranged from 0.90 to 0.97 . The highest correlation values were found between body weight and chest girth $(0.97, \mathrm{p}<0.01)$. Correlation and regression analysis were applied to estimate the relationship among these traits. The study concluded that body weight had a strong correlation with chest girth (0.97), body length (0.92), and body height (0.90).
\end{abstract}

Keywords: Senduro goat, body weight, chest girth, body length, body height

\section{PENDAHULUAN}

Kambing merupakan salah satu ternak yang banyak dipelihara oleh masyarakat luas karena menguntungkan bagi peternak, antara lain perkembangbiakannya cepat, modal yang dibutuhkan relatif kecil, kandang dan pemeliharaannya mudah, serta dapat digunakan sebagai tabungan.

Kambing Senduro merupakan salah satu kekayaan plasma nutfah asli Indonesia yang baru ditetapkan sebagai galur/ras kambing PE oleh Kementerian Pertanian pada tahun 2014 dengan dikeluarkannya Keputusan Kementerian Pertanian No.1055 tahun 2014 (Kementerian Pertanian, 2014). Kambing Senduro merupakan kambing hasil persilangan antara kambing Ettawa, kambing Kacang dan kambing Ja- warandu yang berada di daerah Senduro, Kabupaten Lumajang. Kambing Senduro memiliki keistimewaan jika dibandingkan dengan kambing lainya, yaitu secara kualitatif memiliki warna dominan putih, postur tubuh besar serta memiliki telinga yang panjang. Kambing Senduro merupakan galur/ras kambing PE baru, sehingga perlu dijaga kualitas serta ditingkatkan kuantitasnya dengan meningkatkan produktifitasnya.

Produktifitas seekor ternak dipengaruhi oleh dua faktor utama yaitu genetik dan lingkungan. Faktor genetik menentukan kemampuan produksi, sedangkan lingkungan merupakan pendukung supaya ternak mampu berproduksi sesuai dengan kemampuannya. Faktor lingkungan meliputi pakan, perkandangan, pemeliharaan, 
penyakit dan iklim. Genetik dan lingkungan memiliki peran penting, karena meskipun ternak memiliki genetik yang unggul, tetapi tanpa dukungan pemeliharaan dan pemberian pakan yang baik, produksinya tidak akan maksimal. Sebaliknya meskipun ternak diberikan pakan yang baik tetapi ternak tidak memiliki genetik yang unggul, maka produksinya tidak akan maksimal.

Bobot badan memegang peranan penting dalam pola pemeliharaan yang baik, karena dengan mengetahui bobot badan kambing akan memudahkan penentuan jumlah pemberian pakan, jumlah dosis obat. Bobot badan kambing dapat diketahui dengan dua cara, yaitu dengan penimbangan dan dengan pendugaan. Kedua teknik tersebut masing-masing memiliki keuntungan dan keterbatasan. Metode penimbangan merupakan cara paling akurat namun memiliki banyak kendala, antara lain keterbatasan alat dan tenaga kerja serta dapat menyebabkan cekaman pada kambing. Metode pengukuran bobot hidup kambing yang kedua adalah dengan pendugaan melalui analisis regresi linier antara ukuran statisik vital ternak seperti lingkar dada, panjang badan, lebar dada, dalam dada dengan bobot badan. Kambing Senduro merupakan galur/ras kambing PE baru sehingga perlu dilakukan penelitian tentang hubungan antara statistik vital dengan bobot badan kambing Senduro jantan.

\section{MATERI DAN METODE}

Penelitian ini dilakukan pada tanggal 24 Januari 2016 sampai 24 Februari 2016 di 6 desa di Kecamatan Senduro Kabupaten Lumajang yang meliputi Desa Purworejo, Argosari, Senduro, Burno, Kandangtepus, dan Kandangan. Materi yang digunakan dalam penelitian adalah kambing Senduro jantan sebanyak 104 ekor, terdiri dari 49 ekor PI0, 30 ekor PI2, 7 ekor PI4, 13 ekor PI6 dan 5 ekor PI8. Peralatan yang digunakan dalam penelitian meliputi timbangan gantung merk Morizt dengan kapasitas $200 \mathrm{Kg}$ dan ketelitian $1 \mathrm{Kg}$, pita ukur merk Universal dan tongkat ukur dengan ketelitian masing-masing $1 \mathrm{~mm}$.

Metode yang digunakan dalam penelitian ini adalah survey dengan melakukan pengukuran statistik vital dan penimbangan bobot badan, sedangkan pengambilan sampel dilakukan secara purposive sampling.

\section{Analisa data}

Data yang diperoleh dianalisa menggunakan analisis korelasi dan analisis regresi linear.

$$
r=\frac{\mathrm{n} \sum \mathrm{XY}-\sum \mathrm{X} \sum \mathrm{Y}}{\sqrt{\left(n \sum \mathrm{X}^{2}-\left(\sum \mathrm{X}\right)^{2}\right)\left(n \sum \mathrm{Y}^{2}-\left(\sum \mathrm{Y}\right)^{2}\right)}}
$$

Keterangan:

$r$ : Korelasi

X : Statistik Vital (lingkar dada, panjang badan, tinggi badan)

Y : Bobot badan

n : Jumlah sampel

Besarnya pengaruh ukuran statistik vital terhadap bobot badan kambing Senduro jantan dapat diketahui dari koefisien determinasi dengan rumus sebagai berikut :

$$
\mathrm{R}^{2}=\mathrm{r}^{2} \times 100 \%
$$

Analisa regresi digunakan untuk mengetahui hubungan dari statistik vital (lingkar dada, panjang badan, tinggi badan) dengan bobot badan kambing Senduro jantan menggunakan persamaan sebagai berikut:

Keterangan:

$$
\hat{\mathrm{Y}}=\mathrm{a}+\mathrm{bX}
$$

$\hat{\mathrm{Y}}$ : Bobot badan

$\mathrm{X}$ : Statistik Vital (lingkar dada, panjang badan, tinggi badan) 
a : Konstanta

b : Koefisien regresi

Persentase penyimpangan

pendugaan bobot badan ternak melalui

persamaan regresi dapat diketahui dengan menggunakan perhitungan sebagai berikut:

$$
\% \text { Penyimpangan }=\frac{\text { BB Duga }- \text { BB Nyata }}{\text { BB Nyata }} \times 100 \%
$$

HASIL DAN PEMBAHASAN

\section{Hubungan antara statistik vital dengan bobot badan kambing Senduro jantan}

Nilai korelasi antara statistik vital (X) dengan bobot badan (Y) kambing Senduro Jantan dapat dilihat pada Tabel 1.

Tabel 1. Hubungan antara statistik vital dengan bobot badan kambing Senduro jantan

\begin{tabular}{ccccccc}
\hline \multirow{2}{*}{ Variabel } & \multirow{2}{*}{$\mathrm{N}$} & \multirow{2}{*}{$\mathrm{r}$} & \multirow{2}{*}{$\mathrm{R}^{2}$} & \multirow{2}{*}{$\mathrm{t}$ hitung } & \multicolumn{2}{c}{$\mathrm{t}$ tabel } \\
\cline { 6 - 7 } & & & & & 0,05 & 0,01 \\
\hline LD & 104 & 0,97 & $93,66 \%$ & 9,7292 & 1,9830 & 2,6239 \\
$\mathrm{~PB}$ & 104 & 0,92 & $85,98 \%$ & 9,3250 & 1,9830 & 2,6239 \\
TB & 104 & 0,90 & $82,31 \%$ & 9,1257 & 1,9830 & 2,6239 \\
\hline
\end{tabular}

Keterangan : $\mathrm{N}$ = jumlah sampel; $\mathrm{r}=$ koefisien korelasi; $\mathrm{R}^{2}=$ koefisien determinasi

Hasil penelitian ini

menunjukkan bahwa secara keseluruhan terdapat hubungan positif dan sangat kuat antara statistik vital (lingkar dada, panjang badan dan tinggi badan) dengan bobot badan kambing Senduro jantan. Nilai koefisien korelasi secara berurutan dari yang tertinggi ke rendah yaitu lingkar dada, panjang badan dan tinggi badan, dengan koefisien korelasi masing-masing 0,$97 ; 0,92 ; 0,90$.

Nilai koefisien korelasi antara lingkar dada dengan bobot badan merupakan yang paling kuat jika dibandingkan dengan panjang badan dan tinggi badan, yaitu sebesar 0,97. Hal ini sesuai dengan hasil penelitian Malewa (2009) pada domba Donggala; Basbeth, dkk (2015) pada kambing Jawarandu; Afolayan, et al. (2006) pada domba Yakansa yang melaporkan bahwa lingkar dada memiliki nilai koefisien korelasi yang tertinggi dan sangat kuat yaitu masing-masing 0,91 ; 0,93; 0,94. Hal ini diduga karena lingkar dada berhubungan langsung dengan dada dan ruang abdomen dimana sebagian besar bobot badan ternak berasal dari bagian dada hingga pinggul, sehingga semakin besar ukuran lingkar dada maka bobot badan semakin berat. Soeparno (1992) menyatakan bahwa setiap kenaikan ukuran tubuh maka akan diikuti kenaikan ukuran tubuh lainnya. Dalton (1984) menambahkan bahwa pada ternak ruminansia, saluran-saluran pencernaan yang berada dalam abdomen menyumbang 10-25\% dari bobot hidup.

Panjang badan memiliki nilai korelasi yang kuat dengan bobot badan, yaitu sebesar 0,92. Hal ini sesuai dengan hasil penelitian-penelitian sebelumnya, antara lain Pesmen and Yardimici (2008) yang melaporkan bahwa panjang badan memiliki nilai korelasi yang sangat kuat yaitu sebesar 0,86; Adeyinka and Mohammed (2006) pada kambing di Nigeria Utara sebesar 0,88; Shirzeyli, et al. (2013) pada domba Macoei di Iran yaitu sebesar 0,95; Mahmud, et al. (2014) pada domba jantan yang berumur 13-24 bulan di Nigeria yaitu sebesar 0,948 serta hasil penelitian Sowande and Sobala (2008) pada domba West African Dwarf (WAD) berumur antara 13-36 bulan yaitu sebesar 0,91. Perbedaan hasil nilai korelasi disebabkan oleh perbedaan bangsa ternak yang 
digunakan. Cam, et al. (2010) menyatakan bahwa perbedaan breed, jenis kelamin, aktifitas serta kondisi lingkungan akan menghasilkan respon yang berbeda.

Nilai korelasi antara tinggi badan dan bobot badan pada penelitian ini lebih tinggi jika dibandingkan dengan hasil-hasil penelitian lainnya yakni Trisnawanto, dkk. (2012) pada domba Dombos jantan; Isroli (2001) pada domba Priangan; Afolayan, et al. (2006) pada domba Yakansa yaitu masingmasing 0,$63 ; 0,64 ; 0,84$. Hasil penelitian Jimmy, et al. (2010) menemukan pada kambing jantan dan betina lepas sapih di Uganda sebesar 0,83 dan 0,92; Sowande and Sobala (2008) pada domba WAD (West African Dwarf) dengan umur antara 13-36 bulan yaitu sebesar 0,89 serta Mahmud, et al. (2014) pada domba jantan yang berumur 13-24 bulan di Nigeria yaitu sebesar 0,986. Perbedaan nilai korelasi antara tinggi badan dan bobot badan ini disebabkan oleh perbedaan jenis ternak serta kondisi lingkungan dalam penelitian.

Ukuran tinggi badan memiliki nilai korelasi yang paling rendah jika dibandingkan dengan lingkar dada dan panjang badan. hal ini disebabkan ukuran tinggi badan dipengaruhi oleh pertumbuhan tulang kaki. Selain itu, jaringan otot yang melekat di daerah kaki lebih sedikit jika dibandingkan dengan jumlah jaringan otot yang melekat pada daerah dada dan sepanjang tulang penyusun panjang badan, sehingga tinggi badan memiliki nilai korelasi yang paling rendah. Hal ini sesuai dengan hasil penelitian Sutiyono, dkk. (2006) bahwa tinggi badan dipengaruhi oleh tulang-tulang penyusun kaki depan dan tidak berhubungan langsung dengan ruang abdomen dimana tulang-tulang kaki depan hanya sebagai penunjang aktifitas gerak ternak.

\section{Pendugaan bobot badan kambing Senduro jantan}

Hasil penelitian ini diperoleh persamaan untuk menduga bobot badan kambing Senduro jantan melalui masing-masing persamaan regresi ukuran tubuh dengan bobot badan, rumus Schoorl dan rumus Lambourne serta tingkat penyimpangan pendugaan bobot badan kambing Senduro jantan seperti yang terlihat pada Tabel 2.

Tabel 2. Pendugaan bobot badan melalui persamaan regresi, schoorl dan lambourne serta penyimpangan pendugaan

\begin{tabular}{clcc}
\hline No. & Variabel pendugaan & Persamaan / Rumus & Penyimpangan \\
\hline 1. & Persamaan Regresi LD & $\mathrm{BB}=-79,17+1,67 \mathrm{LD}$ & $9,89 \%$ \\
2. & Persamaan Regresi PB & $\mathrm{BB}=-75,64+1,66 \mathrm{~PB}$ & $14,56 \%$ \\
3. & Persamaan Regresi TB & $\mathrm{BB}=-86,23+1,77 \mathrm{~TB}$ & $16,57 \%$ \\
4. & Schoorl & $\mathrm{BB}=(22+\mathrm{LD})^{2} / 310$ & $28,09 \%$ \\
5. & Lambourne & $\left.\mathrm{BB}=(\mathrm{PBxLD})^{2}\right) / 10050$ & $10,02 \%$ \\
\hline
\end{tabular}

Berdasarkan Tabel 2 dapat diketahui bahwa pendugaan bobot badan menggunakan persamaan regresi lingkar dada memiliki nilai penyimpangan yang kecil yaitu sebesar 9,89\%. Mayaka, et al. (1995) melaporkan bahwa pendugaan bobot badan melalui persamaan regresi lingkar dada memiliki tingkat penyimpangan yang rendah yaitu sebesar 5\% pada kambing di Afrika Barat. Perbedaan hasil penelitian ini disebabkan oleh jenis ternak serta kondisi lingkungan yang berbeda. Sedangkan Wahyudin 
(2007) yang disitasi oleh Malewa (2009) menyatakan bahwa hasil rumus Lambourne lebih mendekati berat sebenarnya dengan tingkat kesalahan di bawah 10\%. Sedangkan tingkat kesalahan pada rumus Schoorl bisa mencapai 22,3\%. Pendugaan bobot badan berdasarkan persamaan regresi lingkar dada pada penelitian ini memiliki tingkat penyimpangan yang rendah jika dibandingkan dengan rumus Lambourne dan Schoorl yang digunakan oleh Malewa (2009). Penggunaan rumus schoorl memiliki nilai penyimpangan yang paling tinggi karena rumus schoorl ditujukan untuk pendugaan bobot badan ternak sapi.

Rendahnya nilai penyimpangan pada persamaan regresi lingkar dada menunjukkan bahwa persamaan regresi lingkar dada dapat dijadikan persamaan/rumus terbaik dalam menduga bobot badan kambing Senduro jantan. Hal ini sesuai dengan Cam, et al. (2010) yang menyatakan bahwa persamaan regresi dapat digunakan untuk menduga bobot badan secara akurat. Zurahmah dan Enos (2011) menyatakan bahwa ukuran lingkar dada merupakan penduga terbaik bobot badan ternak, serta didukung oleh Olatunji and Adeyemo (2009) yang menyatakan bahwa lingkar dada memiliki tingkat keakuratan yang tinggi sehingga dapat digunakan untuk menduga bobot badan ternak.

\section{KESIMPULAN}

Hasil penelitian ini menyimpulkan bahwa ukuran statistik vital kambing Senduro jantan yang meliputi lingkar dada, panjang badan dan tinggi badan memiliki hubungan yang sangat erat dengan bobot badan yang ditunjukkan dari koefisien korelasinya secara berurutan yaitu; 0,97; 0,92; dan 0,90.

\section{DAFTAR PUSTAKA}

Adeyinka, I. A. and I. D. Mohammed. 2006. Relationship of liveweight and linear body mesurement in two breeds of goat of Northen Nigeria. Journal Of Animal and Veterinary Advances. 5(11): 891-893

Afolayan, R. A., I. A. Adeyinka and C. A. M. Lakpini. 2006. The estimation of live weight from body measurements in Yankasa sheep. Czech J. Anim. Sci., 51(8): 343348.

Basbeth, A. H., W. S. Dilaga dan A. Purnomoadi. 2015. Hubungan antara ukuran-ukuran tubuh terhadap bobot badan kambing Jawarandu jantan umur muda di Kabupaten Kendal Jawa Tengah. Animal Agriculture Journal. 4(1): 35-40.

Cam, M. A., M. Olfaz and E. Soydan. 2010. Body measurements reflect body weights and carcass yields in Karayaka sheep. Asian Journal of Animal and Veterinary Advances. 5(2):120127

Dalton, D. C. 1984. An introduction to practical animal breeding. Granada Publishing, Ltd. London

Isroli. 2001. Evaluasi terhadap pendugaan bobot badan domba Priangan berdasarkan ukuran tubuh. Saintek 8(2): 90-94.

Jimmy, S., M. David, K. R. Donald and M. Dennis. 2010. Variability in body morphometric measurements and their application in predicting live body weight of Mubende and small East African goat breeds in Uganda. Middle-East Journal of Scientific Research 5 (2): 98105 
Kementerian Pertanian. 2014. Penetapan galur kambing Senduro. Keputusan Menteri Pertanian Republik Indonesia No. 1055/Kpts/SR.120/10/2014

Mahmud, M. A., P. Shaba, W. Abdulsalam, H. Y. Yisa, J. Gana, S. Ndagi and R. Ndagimba. 2014. Live body weight estimation using cannon bone length and other body linear measurements in Nigerian breeds of sheep. J. Adv. Vet. Anim. Res., 1(4): 169-176.

Malewa, A. 2009. Penaksiran bobot badan berdasarkan lingkar dada dan panjang badan domba Donggala. J. Agroland. 16 (1): $91-97$.

Mayaka, T. B., J. Tchoumboue, Y. Manjeli and A. Teguia. 1995. Estimation of body live weight in West African dwarf from heart grith measurement. J. Trop. Anim. Health. 28: 126128.

Olatunji, A. A. O. and O. K. Adeyemo. 2009. Liveweight and chest girth correlation in commercial sheep and goat herds in Southwestern Nigeria. Int. J. Morphol. 27(1):49-52.

Pesmen, G and M. Yardimici. 2008. Estimating the live weight using some body measurements in Saanen goats. Archiva Zootechnica 11(4): 30-40
Shirzeyli, F. H., A. Lavvaf and A. Asadi. 2013. Estimation of body weight from body measurements in four breeds of Iranian sheep. Songklanakarin Journal Science Technology. 35(5): 507-511.

Soeparno. 1992. Ilmu dan teknologi daging. UGM Press: Yogyakarta.

Sowande, O. S. and O. S. Sobala. 2008. Body measurements of West African dwarf sheep as parameter for estimation of live weight. Trop. Anim. Health Prod. 40: 433-439.

Sutiyono, B., J. W. Nurul dan P. Endang. 2006. Studi performans induk kambing Peranakan Ettawa berdasarkan jumlah anak sekelahiran di Desa Banyuringin Kecamatan Singorojo Kabupaten Kendal. Seminar Nasional Teknologi Peternakan dan Veteriner.

Trisnawanto, R., Adiwinarti dan W. S. Dilaga. 2012. Hubungan antara ukuran-ukuran tubuh dengan bobot badan dombos jantan. Animal Agriculture Journal, 1(1); 653-668.

Zurahmah, N dan T. Enos. 2011. Pendugaan bobot badan calon pejantan sapi Bali menggunakan dimensi ukuran tubuh. Buletin Peternakan. 35(3): 160-164. 